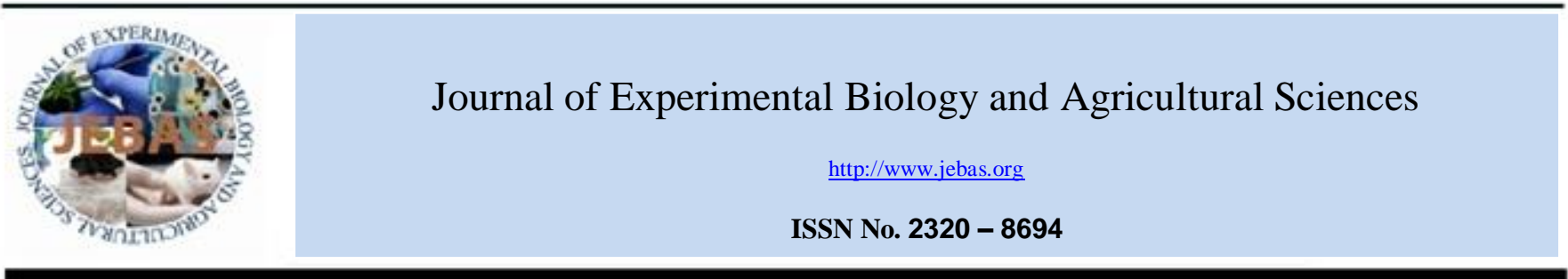

\title{
ASSOCIATION OF THE METABOLIC SYNDROME AND VITAMIN D RECEPTOR GENE POLYMORPHISMS: A CROSS SECTIONAL STUDY
}

\author{
Sawsan O Khoja ${ }^{1,2}$, Yasser El Miedany ${ }^{2,3^{*}}$, Archana P Iyer ${ }^{1,2}$, Sami M Bahlas ${ }^{2,4}$, \\ Khadijah S Balamash ${ }^{1,2}$, Mohamed F Elshal ${ }^{1}$
}

${ }^{1}$ Department of Biochemistry, King Abdulaziz University, Jeddah, Saudi Arabia

${ }^{2}$ Vitamin D Pharmacogenomics research group, King Abdulaziz University, Jeddah, Saudi Arabia

${ }^{3}$ Department of Rheumatology, Darent Valley Hospital, Dartford, Kent, DA2 8DA, England

${ }^{4}$ Department of Internal Medicine, College of Medicine, King Abdulaziz University, Jeddah, Saudi Arabia

Received - July 17, 2017; Revision - November 29, 2017; Accepted - December 22, 2017

Available Online - December 27, 2017

DOI: http://dx.doi.org/10.18006/2017.5(5).899.906

KEYWORDS
Vitamin D
Polymorphisms
Vitamin D Receptor gene
Metabolic syndrome
Parathyroid hormone

* Corresponding author

E-mail: drelmiedany@rheumatology4u.com (Yasser El Miedany)

Peer review under responsibility of Journal of Experimental Biology and Agricultural Sciences.

Production and Hosting by Horizon Publisher India [HPI] (http://www.horizonpublisherindia.in/).

All rights reserved.

\begin{abstract}
The Vitamin D Receptor gene (VDR) expressed in many tissues and are able to modulate the expression of several other genes. The purpose of this study was to assess the association between the metabolic syndrome (MetSyn) and the presence of VDR genes ApaI, BsmI, TaqI and FokI polymorphisms as well as serum levels of vitamin D. Total eighty two (82) individuals were assessed in a cross-sectional study. Enzymatic digestion method was used to detect the VDR polymorphisms and established by allele specific PCR or amplification of refractory mutation. MetSyn was classified based on the National Cholesterol Education Program - Adult Treatment Panel III Assessment of the association of VDR, as well as serum vitamin D level, with MetSyn components was also evaluated. Serum vitamin D levels were significantly low $(p<0.01)$ in MetSyn patients. The occurrence of the genotypes in Apal was significantly different as compared to individuals with MetSyn and the control group $(\mathrm{P}<0.05)$. A negative correlation was reported between MetSyn and 25(OH) vitamin D levels, type-2 diabetes and glucose homeostasis. Further, as compared to individuals without MetSyn, subjects with MetSyn who carry AA genotype had higher waist circumference and BMI. Serum Vitamin D level was also inversely associated with waist circumference $(\mathrm{P}<0.001)$, triglycerides $(\mathrm{P}<0.01)$, haemoglobin A1c $(\mathrm{P}<0.01)$,
\end{abstract}

All the article published by Journal of Experimental Biology and Agricultural Sciences is licensed under a Creative Commons Attribution-NonCommercial 4.0 International License Based on a work at www.jebas.org.

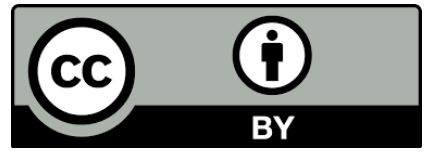


blood pressure $(\mathrm{P}<0.05)$ as well as cardiovascular risk. Using the VDR polymorphism data suggests they may, partially, influence MetSyn. Patients with low serum vitamin D $(25(\mathrm{OH})$ vitamin D) concentrations were at high risk of developing MetSyn. Repletion of Vitamin D might play a role in MetSyn prevention.

\section{Introduction}

Vitamin D plays various important roles such as influencing bone health as well as homeostasis of serum calcium and phosphate levels in human body. In addition, vitamin D also plays an immunoregulatory role and it can modify immune function, cell proliferation, differentiation, and apoptosis (DeLuca, 1988; Reichel et al, 1989). Further, Vitamin D deficiency has been associated with numerous health outcomes, including bone disease, cancer, autoimmune disorders, infectious disease, type 1 and type 2 diabetes, hypertension, and heart disease. Although it is unclear whether or not these associations are causal or regular (Ford et al., 2005). Modulation of the target genes transcription was reported in association with vitamin D activation, via nuclear Vitamin D Receptor (VDR), hence vitamin D may have an impact at the cellular functions level (Filus et al., 2008). Assessment of the VDR gene polymorphisms revealed variable pattern including ApaI (VDR $7975232 \mathrm{C}>\mathrm{T}$ ), BsmI (VDR 1544410 A $>$ G), FokI (VDR $2228570 \mathrm{C}>\mathrm{T}$ ), and TaqI (VDR $731236 \mathrm{~T}>\mathrm{C}$ ). Amongst these, some polymorphisms were reported to be associated with insulin secretion, obesity related metabolic changes as well as type 2 diabetes mellitus (Ortlepp et al., 2001; Ogunkolade et al., 2002).

Metabolic syndrome (MetSyn) is a cluster of risk factors that predispose to cardiovascular morbidity and mortality (Wilson et al., 2005). MetSyn was associated with 3-5 folds higher risk for the development of type II diabetes Mellitus. Based on the NCEPATP III diagnostic criteria 1 for MetSyn, there is $24 \%$ prevalence among adults in the USA (Ford et al., 2002). In the gulf region, the prevalence was reported at $21 \%$ in Oman (Al-Lawati et al., 2003), 18\% in Kuwait (Hanan et al., 2008), whereas in Saudi Arabia, the estimated prevalence MetSyn varied from 20.8\%$39.3 \%$ (Al-Qahtani \& Imtiaz, 2005). Furthermore, it was reported that $72.4 \%$ of Saudis over the age of 40 suffer from obesity, and $35.6 \%$ in Saudi society, of whom $44 \%$ are women and $26.4 \%$ of men, are obese. The rate of obesity among Saudi children was rated at about $18 \%$ (Al-Nozha et al., 2005).

Although the relationship between vitamin D deficiency/ insufficiency and components of MetSyn has been already reported in earlier studies (Pittas et al., 2007; Barrimah et al., 2009), few studies have assessed VDR gene polymorphisms for associations with the risk of these disorders (Ye et al., 2001; Ford et al., 2005;). On the other hand, various studies have demonstrated moderate to high heritability for circulating vitamin D levels. Accordingly, many studies have investigated the genetic determinants of this hormone. Recent advances in the methodology of large-scale genetic association studies, helped to identify the genetic determinants of vitamin D levels and study its correlations to various diseases (Oh \& Barrett-Connor, 2002; Wang et al., 2010). Therefore, identifying the association between vitamin D serum levels, its genetic predisposition, and the occurrence of MetSyn, would have important therapeutic implications in standard clinical practice. This study was carried out aiming at the assessment of the association of the MetSyn components and VDR gene polymorphism.

\section{Materials and Methods:}

\subsection{Study design}

A randomized cross-sectional study which included 82 Saudi individuals who were managed and monitored in King Abdulaziz University Hospital in Jeddah. Local ethical and methodological protocols adopted in King Abdulaziz University, Jeddah has been strictly followed during the study. All patients who had participated in the study signed an informed consent according to the Declaration of Helsinki (at the General Assembly in October 2008).

\subsection{Participants}

This study included Saudi adults aged between 20 to 50 years reviewed for routine check up at outpatient clinics, King Abdulaziz University Hospital in Jeddah. Socio-demographic characteristics, relevant history, physical examination and educational level were undertaken and recorded. During study, the pre-decided exclusion criteria were: the presence of chronic illnesses potentially which might alter or affect the metabolism of vitamin $\mathrm{D}$, taking vitamin $\mathrm{D}$ supplement therapy, pregnancy or breast feeding or taking any medications which may impact on bone metabolism. After the proper selection of the subjections according to the inclusion and exclusion criteria as well as excluding the individuals who did not agree to participate in this work, 82 blood samples were collected for laboratory testing and genotyping. 


\subsection{Clinical assessment and anthropometric measures}

Body weight of the subjects involved in this study was taken using Seca electronic scale (Seca GmbH Corporation., Hamburg, Germany); whereas their height was measured by using a fixed stadio meter with a vertical backboard and movable headboard. Body mass index was calculated, based on the equation: "BMI = Weight $(\mathrm{kg}) /$ Height $(\mathrm{m})^{2}$ ", Obesity was considered if BMI $>30.0$ $\mathrm{kg} / \mathrm{m}^{2}$, whereas overweight was considered if the BMI was in the range of $25-29.9 \mathrm{~kg} / \mathrm{m}^{2}$ Measuring waist circumference was recorded whilst the subjects were standing. Blood pressure was obtained by using an automatic blood pressure monitor (Philips Sure Signs VS3 model, Amsterdam, Netherland). Three blood pressures measures were recorded at rest, with five minutes intervals apart. The average of the 3 measurements was calculated and used for this study. The use of sunscreen and practice of outdoor physical activities was also recorded.

\subsection{The diagnosis of Metabolic Syndrome}

Participants were stratified into two groups, with and without MetSyn, based on NCEP - ATP III criteria (Weyland et al., 2014) which require 3 of the following (i). Abdominal/central obesity (waist circumference) $\geq 102 \mathrm{~cm}$ (40 inches) in men and $\geq 88 \mathrm{~cm}$ (35 inches) in women; (ii) Hypertriglyceridaemia $\geq 1.7 \mathrm{mmol} / \mathrm{L}$; (iii) $\mathrm{HDL}-\mathrm{C}$ level $\leq 1 \mathrm{mmol} / \mathrm{L}$ for men and $\leq 1.3 \mathrm{mmol} / \mathrm{L}$ for women and (iv) Raised blood pressure $\geq 130 / 85$; 5 . Impaired $\mathrm{FBG} \geq 110 \mathrm{mg} / \mathrm{dL}(6.1 \mathrm{mmol} / \mathrm{L})$

\subsection{Clinical assessment}

Based on diagnostic criteria, the case control study included 41 cases with MetSyn and 41 controls. Using a standard closedended questionnaire, trained persons interviewed all the participants. Data regarding general demographic characteristics, level of educational, history of smoking, physical activity status, blood pressure, lipid, and sugar, as well as related co-morbidities (including hypertension, diabetes, coronary heart disease, stroke, family history, and current/past medical treatment) were recorded. Cardiovascular risk was calculated using Qrisk 2.

\subsection{Biochemical analysis and blood sampling}

\subsubsection{Serum vitamin D Level assessment}

From each subject, six ml blood was collected in (EDTA) tubes and separated within 12 hours by centrifugation at $1,500 \mathrm{rpm}$ [acceleration, 9; deceleration, 9 (with break)] for 5 minutes at $4^{\circ} \mathrm{C}$ for serum collection. The serum was stored at $-80^{\circ} \mathrm{C}$ until analysis.

Vitamin D3 levels were determined by using a quantitative sandwich ELISA, according to the manufacturer's protocol (Human 25 Hydroxy Vitamin D3 (25OHV D3). Elisa kit Cat. No.
(MBS722906) My BioSource, Inc. San Diego, CA, USA). The results were measured spectrophotometrically at a wavelength of $450 \mathrm{~nm}$ using microplate reader (ELx808, Biotek Instruments, Inc., Winooski, VT, USA). Total Vitamin D (VitD3+D2) levels were determined using the ADVIA Centaur according to the manufacturer's specifications (ADVIA Centaur product code 10699201, Siemens Healthcare Diagnostics Inc. Tarrytown, NY).

\subsubsection{Genotyping:}

\subsubsection{Polymerase chain reaction (PCR)}

Using the QIAamp DNA Blood Mini kit (cat. no. 51104; Qiagen, Hilden, Germany), Genomic DNA was extracted. The extracted DNA was stored at $-20^{\circ} \mathrm{C}$ for polymerase chain reaction (PCR) amplification. Nanodrop2000c (Thermo Fisher Scientific, Inc.) was used to assess the purity and the concentration of the extracted DNA.

Preparation of the PCR reaction mixture was carried out using the Maxima Hot Start Green PCR Master Mix (2X; cat. no. K1061; Thermo Fisher Scientific, Inc.). The primers obtained from Biolegio (the Netherlands) were indistinguishable from those used by Grundy et al. (2005) (forward, 5' -CAA CCA AGA CTA CAA GTA CCG CGT CAG TGA-3' and reverse, 5'-GCA ACT CCT CAT GGC TGA GGT CTC-3'). The reaction mixture contained $25 \mu 12 \mathrm{X}$ master mix (including reaction buffer, $4 \mathrm{mM} \mathrm{Mg} 2+4$ $\mu \mathrm{M}$ deoxyribonucleoside triphosphates and $0.45 \mathrm{U}$ Taq DNA polymerase), $0.2 \mu \mathrm{M}$ of each primer ( $4 \mu 1$ of a $100-\mu \mathrm{M}$ stock solution), 10-30 ng DNA template $(12 \mu \mathrm{l})$ and $5 \mu \mathrm{l}$ nuclease-free water to reach a final volume of $50 \mu 1$. PCR amplification was performed in a GeneAmp® PCR System 9700 (Model no. N805S3052708; Applied Biosystems; Thermo Fisher Scientific, Inc.) with the following thermocycling conditions: Initial step: 1. denaturation at $95^{\circ} \mathrm{C}$ for $4 \mathrm{~min}$; followed by 2.30 cycles of denaturation at $95^{\circ} \mathrm{C}$ for 30 seconds; 3.annealing at $60^{\circ} \mathrm{C}$ for 1 $\min$; and 4. extension at $68^{\circ} \mathrm{C}$ for $2 \mathrm{~min}$, followed by 5 . a final extension at $72^{\circ} \mathrm{C}$ for $5 \mathrm{~min}$ and hold at $4^{\circ} \mathrm{C}$.

The PCR amplification products were resolved on $1 \%$ agarose gels stained with ethidium bromide (both from Promega Corp., Madison, WI, USA). DNA loading dye (R0611) and DNA ladder (SM0314) ranging from 250 to 10,000 bp (both from Thermo Fisher Scientific, Inc.) were used in each gel. An M03 2746 Gel Documentation system (UVitec, Cambridge, UK) was used to visualize the PCR products.

Restriction fragment length polymorphism (RFLP) analysis of VDR. Amplified PCR products $(5 \mu \mathrm{l})$ were digested with 3,000 U of each restriction enzyme (ApaI, BsmI, FokI and TaqI; Thermo Fisher Scientific, Inc.) according to the manufacturer's protocols. The mixture was incubated for 1 hour in a thermocycler at $37^{\circ} \mathrm{C}$, 
at which the enzymes are active, followed by inactivation by incubation at $65^{\circ} \mathrm{C}$ for $20 \mathrm{~min}$. RFLP products were electrophoresed on $2 \%$ agarose gels.

\subsection{Statistical analysis:}

Data analysis used the Statistical Package for Social Sciences (SPSS 16), SPSS Inc., Chicago, Illinois, USA. Data were expressed as mean and standard deviation (SD). ANOVA (oneway of analysis of variables) was used to study the relation between the genotypes and the variation in different MetSyn components. The student t-test was used to examine the differences between the genotypes in studied parameters. The allele and genotype frequencies were compared using the Chi square (X2) method, to determine whether any significant differences in polymorphism frequencies occurred between the patients and control subjects. The odds ratio (OR) was calculated, when significant $\mathrm{P}$-values were generated. The association between the disease as well as its genotypes was assessed using odds ratios and $95 \%$ confidence intervals (CI). P-value $<0.05$ was used as the statistical set point.

\section{Results}

\subsection{Participants' characteristics}

There were no statistically significant differences among the treatment groups with regard to age, sex, disease duration, socioeconomic status, or other comorbidities. The study group (41 patients) mean age was $51.2 \pm 8.3$ years, whereas in the control group (41 patients) it was $50.7 \pm 8.7$ years. Studying female: male ratio, revealed that females composed $60.9 \%(28 / 46)$ in the MetSyn group, whereas in the control group they formed $60 \%$ (27/45). As compared to controls, individuals with MetSyn had significantly higher BMI, waist circumference, blood pressure, fasting glucose, and triglycerides whereas HDL cholesterol serum levels were lower. Table 1 depicts a comparison of the baseline data in both groups assessed.

\subsection{Serum Vitamin D:}

MetSyn patients had significantly lower levels of serum vitamin D $(\mathrm{p}<0.01)$. Assessing the association between serum vitamin $\mathrm{D}$ and MetSyn components; revealed a negative relationship between $25(\mathrm{OH})$ vitamin $\mathrm{D}$ levels and type-2 diabetes, glucose homeostasis, as well as metabolic syndrome. Serum Vitamin D level was also inversely associated with waist circumference $(\mathrm{P}<$ 0.001), triglycerides $(\mathrm{P}<0.01)$, haemoglobin A1c $(\mathrm{P}<0.01)$, blood pressure $(\mathrm{P}<0.05)$ as well as cardiovascular risk (table2).

\subsection{VDR polymorphisms and MetSyn}

The difference in the occurrence of the genotypes in Apal between individuals with MetSyn and the control group was significant
Table 1 Baseline characteristics in patients with metabolic syndrome versus those without assessed in this study

\begin{tabular}{|c|ccc|}
\hline & MetSyn & Non-MetSyn & P Value \\
\hline Male/Female, $n$ & $99 / 292$ & $100 / 300$ & 0.917 \\
\hline Age & $53.37 \pm 10.99$ & $52.93 \pm 11.08$ & 0.997 \\
\hline Height $(\mathrm{cm})$ & $167.09 \pm 8.11$ & $166.73 \pm 7.34$ & 0.118 \\
\hline Weight(kg) & $103.19 \pm 10.15$ & $87.09 \pm 7.90$ & $<0.01$ \\
\hline BMI & $36.09 \pm 2.97$ & $31.53 \pm 2.72$ & $<0.01$ \\
\hline WC(cm) & $109.70 \pm 6.63$ & $94.11 \pm 7.47$ & $<0.001$ \\
\hline BPS(mmHg) & $136.88 \pm 20.38$ & $124.87 \pm 18.29$ & $<0.001$ \\
\hline BPD(mmHg) & $84.13 \pm 11.55$ & $77.19 \pm 11.01$ & $<0.001$ \\
\hline FBG(mmol/L) & $7.57 \pm 1.31$ & $5.58 \pm 0.83$ & $<0.001$ \\
\hline TG(mmol/L) & $2.07 \pm 1.19$ & $1.30 \pm 1.16$ & $<0.001$ \\
\hline $\begin{array}{c}\text { HDL- } \\
\text { C }(\mathrm{mmol} / \mathrm{L})\end{array}$ & $1.28 \pm 0.38$ & $1.48 \pm 0.34$ & $<0.001$ \\
\hline
\end{tabular}

MetSyn: Metabolic Syndrome.

Table 2 Logistic regression analyses of variables associated with serum vitamin D in MetSyn patients

\begin{tabular}{|ll|} 
Variable & OR $(95 \% \mathrm{CI})$ \\
\hline Age, years & $1.02(1.06-1.35)$ \\
\hline BMI, kg/m2 & $1.67(0.92-1.43)$ \\
\hline Waist circumference & $0.94(0.57-0.96)$ \\
\hline Triglycerides & $1.82(1.86-2.41)$ \\
\hline Systolic Blood pressure & $1.52(0.84-6.15)$ \\
\hline Fasting blood sugar & $-1.14(0.78-1.21)$ \\
\hline ApaI & $0.99(0.72-1.06)$ \\
\hline
\end{tabular}

( $\mathrm{P}<0.05)$. The frequencies of genotype AA in the control group were $23.3 \%$, whereas it was $66.7 \%$ in subjects living with MetSyn; suggesting that the genotype AA could be a risk factor $(\mathrm{P}<0.05 ; \mathrm{OR}=1.651)$. In comparison to the genotype $\mathrm{AA}$, genotype Aa was likely to be a protective factor $(\mathrm{P}<0.001$; $\mathrm{OR}=0.674$ ). As far as the other gene receptors assessed, there was no significant evidence to be risk factors or protective factors to Bsml, Taql, as well as FokI polymorphism in individuals with MS (Table 3).

\subsection{The associations of VDR gene polymorphisms with the components of MetSyn}

Outcomes of assessment of the distribution of clinical variables in relation to the genotypes observed in individuals with and without MetSyn; individuals with MetSyn carrying AA genotype was 
Table 3 Metabolic Syndrome relationship with Vitamin D receptor Genes Polymorphism

\begin{tabular}{|c|c|c|c|}
\hline & MetSyn & $\begin{array}{c}\text { Non } \\
\text { MetSyn }\end{array}$ & \\
\hline $\begin{array}{l}\text { Vitamin D3 } \\
\text { Mean }(S D)\end{array}$ & $6.5(4.5)$ & $14.5(5.8)$ & $0.01 *$ \\
\hline \multicolumn{4}{|l|}{ Apal (\%) } \\
\hline - $\quad \mathrm{AA}$ & $4(66.7)$ & $8(23.3)$ & \multirow{3}{*}{$0.05 *$} \\
\hline - $\mathrm{Aa}$ & 0 & $11(40.0)$ & \\
\hline - $\quad$ aa & $2(33.3)$ & $11(36.7)$ & \\
\hline \multicolumn{3}{|l|}{ Bsml (\%) } & \\
\hline - $\quad \mathrm{BB}$ & $2(33.3)$ & $8(26.7)$ & \multirow{3}{*}{$0.897 \mathrm{NS}$} \\
\hline - $\quad \mathrm{Bb}$ & $2(33.3)$ & $13(43.3)$ & \\
\hline - $\quad b b$ & $2(33.3)$ & $9(30.0)$ & \\
\hline \multicolumn{3}{|l|}{ Taql (\%) } & \\
\hline • $\quad \mathrm{TT}$ & $2(33.3)$ & $10(32.3)$ & \multirow{3}{*}{$0.399 \mathrm{NS}$} \\
\hline - $\mathrm{Tt}$ & $3(50.0)$ & $8(25.8)$ & \\
\hline - $\quad \mathrm{tt}$ & $1(16.7)$ & 13 (41.9) & \\
\hline \multicolumn{3}{|l|}{ FOK1 } & \multirow{3}{*}{$1.00 \mathrm{NS}$} \\
\hline - $\quad \mathrm{Ff}$ & $1(16.7)$ & $7(22.6)$ & \\
\hline - $\quad \mathrm{ff}$ & $5(83.3)$ & $24(77.4)$ & \\
\hline
\end{tabular}

associated with higher waist circumference and BMI than individuals without MetSyn. Similarly, subjects with AA genotype higher systolic blood pressure than those with Aa/aa genotype $(p<0.01)$. Otherwise, the values of the variables assessed were very similar among all subjects for VDR Bsml, Taql, as well as FokI polymorphisms.

\section{Discussion}

Results of this work revealed significantly low serum vitamin D levels in patients with MetSyn and that there is a relationship between 25(OH) vitamin D levels and glucose homeostasis, metabolic syndrome as well as type 2 diabetes. These results are in agreement with earlier published data which revealed that low serum vitamin D $(25(\mathrm{OH})$ vitamin $\mathrm{D})$ concentrations are associated with increased risk of metabolic syndrome development (Newton et al., 1989; Gagnon et al., 2012). In a prospective study carried out by Gagnon his colleagues (Newton et al., 1989), 4164 adults (mean age 50 years; $58 \%$ women) were monitored for 5 years. Results of this study revealed that 528 incident cases $(12.7 \%)$ were identified to have MetSyn. The Metabolic syndrome risk was significantly higher in subjects with very low serum vitamin $D$ in the first $(<18 \mathrm{ng} / \mathrm{mL})$ as well as second $(18-23 \mathrm{ng} / \mathrm{mL})$ quintiles [OR $=1.41$ (95\%CI: $1.02-1.95)$ and 1.74 (95\%CI:1.28-2.37) respectively]. Similar study carried out by Kayaniyil et al. (2014), on a multi-ethnic cohort of nondiabetic adults with pre-existing risk factors in Ontario, Canada; prospective association of serum vitamin D was reported with the metabolicsyndrome.489 subjects with MetSyn were monitored over a 3-year follow-up period. After adjustment for sociodemographics, including baseline and change in supplement use, season, physical activity and insulin resistance; multivariate logistic regression analyses was revealed a decreased risk of the metabolic syndrome per standard deviation increase in baseline 25(OH)D (OR = 0.63,95\%CI: 0.44-0.90)(Gagnon et al., 2012).

Studying the relation of serum vitamin $\mathrm{D}$ and the defining components of MetSyn, results of this work revealed that serum Vitamin D level was inversely associated with waist circumference $(\mathrm{P}<0.001)$, triglycerides $(\mathrm{P}<0.01)$, haemoglobin $\mathrm{A}_{1} \mathrm{c}(\mathrm{P}<0.01)$, blood pressure $(\mathrm{P}<0.05)$ as well as cardiovascular risk. This was confirmed by the multiple logistic regression analysis. Karatas et al. (2013) studied the association between Metabolic Syndrome components and 25(OH) vitamin D levels, in 287 Turkish subjects. Among these subjects cohort, 214 participants were either obese (BMI $>30 \mathrm{~kg} / \mathrm{m} 2)$ ) or overweight (BMI: 25-29.9 kg/m2). After correction for age, season and gender, multiple logistic regression analyses were carried out with metabolic syndrome, hypertension, abdominal obesity, hypertriglyceridemia as well as low HDL-C, as the dependent variable; and with $25(\mathrm{OH})$ vitamin $\mathrm{D}$ as a continuous independent variable. Hypo-vitamin osis D was significantly more common in the overweight/obese individuals with and without the metabolic syndrome. A significant inverse relationship was reported between serum $25(\mathrm{OH})$ vitamin D concentration and serum levels of triglycerides. Non-significant associations were observed between serum 25(OH) vitamin D levels MetSyn components namely insulin resistance, hypertension, and HDL-C. The relationship between vitamin D status (reflected in serum $25(\mathrm{OH})$ vitamin $\mathrm{D}$ concentrations) and the adipose tissue volume remains indistinct. As adipose tissue is one of the places where vitamin D is sequestered, it has been suggested that by increasing the distribution of available adiposity volume, such as in obesity, may induce lowering of the levels of serum vitamin D (Wortsman et al., 2000; Blum et al., 2008). Contradictory opinion was proposed by Pramyothin et al. (2011) who assessed for the vitamin D levels in the subcutaneous abdominal fat taken from 17 patients undertaking gastric bypass surgery. In addition to measuring Vitamin D at surgery, it was also monitored over a 12-month follow-up period. Results of the study revealed that vitamin D levels in the adipose tissue varied noticeably during the follow-up period, in spite of regular intake of vitamin D supplements (> $2500 \mathrm{IU} /$ day), whereas there was no significant change in serum 25(OH) vitamin D levels. 
The results of this study showed a linkage between VDR and MetSyn. Four VDR gene polymorphisms were assessed in subjects with and without MetSyn. Results revealed that in contrast to subjects subgroup without MetSyn, MetSyn patients had, significantly, more frequent AA genotype and the A allele of VDR ApaI polymorphism. Otherwise there were no significant differences regarding BsmI, TaqI and FokI alleles. Earlier studies revealed variable associations between VDR receptor genes and MetSyn. Results of the study done by Bid et al. (2009) did not reveal any significant association between diabetes risk and VDR (FokI, BsmI and TaqI) genotypes in the north Indian population. Similarly, in another study, done by Malecki et al. (2003), on Polish population, no association was reported between VDR FokI, ApaI, BsmI and TaqI polymorphisms and diabetes risk. The discrepancy between the outcomes of these studies and the results of our study could belinked to, or elucidated by, the genetic differences amongst the studied populations or their exposure to different environmental factors. A study was carried out by Mackawy \& Badawy (2014) to investigate the functional aspects of the VDR polymorphisms. The study included measurement of several clinical and metabolic parameters of the patients and controls and outcomes revealed that VDR gene polymorphisms may influence the severity of MetSyn component disorder.

Though there was no association of glycemia with any of the VDR gene polymorphisms, results of this work sowed positive association between serum vitamin $\mathrm{D}$ level and Hemoglobic $\mathrm{A}_{1} \mathrm{C}$. This highlights the importance of vitamin $\mathrm{D}$ assessment for all patients diagnosed with MetSyn, or those who have one or more of its components, with views toward repletion whenever indicated. Recent studies are in favour of the vascular protective vitamin D role, against the advanced glycation end products effects, which have been proposed as mediator for the distressing cardiac complications reported in diabetic patients (Wang, 2013). The positive vitamin D role was attributed to its impact on insulin synthesis enhancement and release, increasing the insulin receptors expression, hence suppress the inflammatory process. These three mechanisms have been proposed to explain the positive role of vitamin $\mathrm{D}$ in reducing the potential insulin resistance risks (Scragg et al., 2004). Furthermore, the VDR polymorphism association with the subjects' BMI and waist circumference as well as lipid profile measures; provides an enlightenment of the vitamin D role in reducing adiposity. Therefore, the vitamin $\mathrm{D}$ role in the potential reduction of adiposity, improvement of insulin sensitivity as well as the inverse relation between vitamin D status and increased adiposity are key factors for consideration when evaluating the relationship of vitamin $\mathrm{D}$ with both diabetes and its associated comorbidities as well as insulin resistance.

In conclusion, vitamin $\mathrm{D}$ whether acting solely or as part of a pathway, serves to promote health and reduce the risks of MetSyn onset or any of its components. Therefore, Vitamin D repletion is vital to prevent such disorders. Examining genetic polymorphisms on a larger sample size to stratify individuals who are more likely to develop MetSyn or based on their vitamin D status in recommended.

\section{Competing Interest}

The authors have no relevant financial disclosures.

\section{Authors Contribution}

S. Khoja and Y. El Miedany conceived and designed the experiments; Dr. Archana and Elshal performed the experiments; All Authors analyzed the data; S.Khoja, Y El Miedany, S. Bahlas and, K. Balamash wrote the paper; All the authors reviewed the manuscript".

\section{Funding}

This project was funded by the Deanship of Scientific Research (DSR) at King Abdulaziz University, Jeddah, under grant no. RG10-130-136. The authors acknowledge therefore with thanks DSR. for technical and financial support.

\section{Acknowledgement}

We express thanks to all participants, our colleagues, research assistants and nurses for their cooperation and help to bring this research to its final conclusions.

\section{Ethics Approval}

King Abdulaziz University Research Ethics Board, Jeddah, Saudi Arabia.

\section{Conflict of Interest}

Nothing to Declare

\section{References}

Al-Lawati JA, Mohammed AJ, AL-Hinai HQ, Jousilathai $\mathrm{P}$ (2003) Prevalence of the metabolic syndrome among Omani adults. Diabetes Care 26:1781-1785.

Al-Nozha M, Al-Khadra A, Arafah MR, Al-Maatouq MA, Khalil MZ, Khan NB, Al-Mazrou YY (2005) Metabolic syndrome in Saudi Arabia. Saudi Medical Journal 26:1918-1925

Al-Qahtani DA, Imtiaz ML (2005) Prevalence of metabolic syndrome in Saudi adult soldiers. Saudi Medical Journal 26:13601366.

Barrimah IE, Mohaimeed AR, Midhat F, Al-Shobili HA 
(2009) Prevalence of metabolic syndrome among Qassim University personnel in Saudi Arabia. International Journal Health Science 3:133-142. ( $\checkmark$ ).

Bid HK, Konwasr R, Aggarwal CG, Gautam S, Saxena M, Nayak VL, Banerjee M (2009) Vitamin D receptor (FolkI, BsmI and TaqI) gene polymorphisms and type 2 diabetes mellitus: a North Indian study. Indian Journal Medical Sciences 63: 187-194. http:// hdl.handle.net/1807/55224.

Blum M, Dolnikowski G, Seyoum E, Harris SS, Booth S, Peterson J, Saltzman E, Dawson-Hughes B (2008) Vitamin D3 in fat tissue. Endocrine 33: 90-94 DOI:10.1007/s12020-008-9051-4.

DeLuca HF (1988) The vitamin D story: a collaborative effort of basic science and clinical medicine. Journal Federation of American Societies for Experimental Biology 2:224-236.

Filus A, Trzmiel A, Kuliczkowska-Plaksej J, Tworowska U, Jedrzejuk D, Milewicz A, Medras M (2008) Relationship between vitamin D receptor BsmI and FokI polymorphisms and anthropometric and biochemical parameters describing metabolic syndrome. Aging Male 11:134-139. doi: 10.1080/13685530802273426.

Ford ES, Ajani UA, McGuire LC, Liu S (2005) Concentrations of serum vitamin D and the metabolic syndrome among U.S. adults. Diabetes Care 28:1228-1230. doi: 10.2337/diacare.28.5.1228.

Ford ES, Giles WH, Dietz WH (2002) Prevalence of the metabolic syndrome among US adults' findings from the third national health and nutrition examination survey. Journal American Medical Association 287: 356-359.

Gagnon C, Lu ZX, Magliano DJ, Dunstan DW, Shaw JE, Zimmet PZ, Sikaris K, Ebeling PR, Daly RM (2012) Low serum 25 hydroxyvitamin $\mathrm{D}$ is associated with increased risk of the development of the metabolic syndrome at five years: results from a national, population based prospective study (The Australian Diabetes, Obesity and Lifestyle Study: AusDiab). The Journal of Clinical Endocrinology \& Metabolism 97: 1953-1961 [DOI: 10.1210/jc2011-3187

Grundy SM, Cleeman JI, Daniels SR, Donato KA, Eckel RH, Franklin BA, Gordon DJ, Krauss RM, Savage PJ, Smith SC, Spertus JA, Costa F (2005) Diagnosis and management of the metabolic syndrome: an American Heart Association/National Heart, Lung, and Blood Institute Scientific Statement. Circulation $112: 2735-2752$. doi: 10.1161/CIRCULATIONAHA.105.169404.
Badr HE, Al Orifan FH, Amasha MM, Khadadah KE, Younis $\mathrm{HH}$, Se'adah MA. Prevalence of metabolic syndrome among healthy Kuwaiti adults: Primary health care centers based study. Middle East J Family Med. 2007;5:30-6.

Karatas S, Hekimsoy Z, Dinc G, Onur E, Ozmen B (2013) Vitamin D levels in overweight/obese adults with and without metabolic syndrome. Journal of Endocrinology and Metabolism 3: 47-56. DOI: $10.4021 /$ jem166e.

Kayaniyil S, Harris SB, Retnakaran R, Vieth R, Knight J, Gerstein H, Perkins B, Zinman B, Hanley A (2014) Prospective association of $25(\mathrm{OH}) \mathrm{D}$ with metabolic syndrome. Clinical Endocrinology 80: 502-507.

Mackawy A, Badawi M (2014) Association of vitamin D and vitamin D receptor gene polymorphisms with chronic inflammation, insulin resistance and metabolic syndrome components in type 2 diabetic Egyptian patients. Meta Gene 2: 540-556.

Malecki MT, Frey J, Moczulski D, Klupa T, Kozek E, Sieradzki J (2003) VDR gene polymorphisms and association with type 2 diabetes mellitus in a Polish population. Experimental Clinical Endocrinology and Diabetes 111: 505-509.

Newton CR, Graham A, Heptinstall LE, Powell SJ, Summers C, Kalsheker N, Smith JC, Markham AF (1989) Analysis of any point mutation in DNA. The Amplification Refractory Mutation System (ARMS) Nucleic Acids Research 17 : 2503-2516. doi: 10.1093/nar/17.7.2503.

Ogunkolade BW, Boucher BJ, Prahl JM, Bustin SA, Burrin JM, Noonan K, North BV, Mannan N, McDermott MF, DeLuca HF, Hitman GA (2002) Vitamin D Receptor (VDR) mRNA and VDR Protein Levels in Relation to Vitamin D Status, Insulin Secretory Capacity, and VDR Genotype in Bangladeshi Asians. Diabetes 51:2294-2300. doi: 10.2337/diabetes.51.7.2294.

Oh JY, Barrett-Connor E (2002) Association between vitamin D receptor polymorphism and type 2 diabetes or metabolic syndrome in community-dwelling older adults: the Rancho Bernardo Study. Metabolism 51:356-359. doi: 10.1053/meta.2002.29969.

Ortlepp JR, Lauscher J, Hoffmann R, Hanrath P, Joost HG (2001) The vitamin $\mathrm{D}$ receptor gene variant is associated with the prevalence of type 2 diabetes mellitus and coronary artery disease. Diabetes Medication 18:842-845.

Pittas AG, Harris SS, Stark PC, Dawson-Hughes B (2007) The effects of calcium and vitamin D supplementation on blood 
glucose and markers of inflammation in nondiabetic adults. Diabetes Care 30:980-986. doi: 10.2337/dc06-1994.

Pramyothin P, Biancuzzo RM, Lu Z, Hess DT, Apovian CM, Holick MF (2011) Vitamin D in adipose tissue and serum 25hydroxyvitamin D after roux-en-Y gastric bypass. Obesity 19: 2228-2234. DOI: 10.1038/oby.2011.17.

Reichel H, Koeffler HP, Norman AW (1989) The role of the vitamin D endocrine system in health and disease. New England Journal of Medicine 320:980-991. doi: 10.1056/NEJM198904133201506.

Scragg R, Sowers M, Bell C (2004) Serum 25-hydroxivitamin D, diabetes, and ethnicity in the Third National Health and Nutrition Examination Survey. Diabetes Care 27: 2813-2818.

Wang C (2013) Role of vitamin D in cardiometabolic diseases. Journal Diabetes Research, http://dx.doi.org/10.1155/2013/243934 (Article ID 243934, 10 pp.).

Wang TJ, Zhang F, Richards JB, Kestenbaum B, Meurs JB, Berry D, Kiel D, Streeten E, Ohlsson C, Koller D, Peltonen L, Cooper
J, O'Reilly P, Houston D, Glazer N, Vandenput L, Peacock M, ShiMScw J, Spector T (2010) Common genetic determinants of vitamin D insufficiency: a genome-wide association study. Lancet 367: $180-188$.

Weyland PG, Grant WB, Howie-Esquivel J (2014) Does sufficient evidence exist to support a causal association between vitamin D status and cardiovascular disease risk? An assessment using Hill's criteria for causality. Nutrients 6: 3403-3430.

Wilson PW, D'Agostino RB, Parise H, Sullivan L, Meigs JB (2005) Metabolic syndrome as a precursor of cardiovascular disease and type 2 diabetes mellitus. Circulation 112:3066-3072.

Wortsman J, Matsuoka LY, Chen TC, Lu Z, Holick MF (2000) Decreased bioavailability of vitamin D in obesity. American Journal Clinical Nutrition 72: 690-693.

Ye WZ, Reis AF, Dubois-Laforgue D, Bellanne-Chantelot C, Timsit J, Velho G (2001) Vitamin D receptor gene polymorphisms are associated with obesity in type 2 diabetic subjects with early age of onset. European Journal of Endocrinology 145:181-186. doi: 10.1530/eje.0.1450181. 